\title{
Quiz: um Questionário Eletrônico para Autoavaliação e Aprendizagem em Genética e Biologia Molecular
}

\author{
Quiz: an Electronic Questionnaire for \\ Self-assessment and Learning in Genetics \\ and Molecular Biology
}

\author{
João Miguel de Almeida Silva \\ Rafael Vieira Canedo \\ Thomas Alves de Souza Abrantes \\ Rafael Teixeira dos Santos ${ }^{1}$ \\ Renata Almeida Souza ${ }^{I I}$ \\ Claudia Yamada Utagawal
}

PALAVRAS-CHAVE

- Educação Médica.

- Materiais de Ensino.

- Informática Médica.

KEYWORDS

- Medical Education.

- Teaching Materials.

- Medical Informatics.

Recebido em: 17/09/2009

Reencaminhado em: 28/01/2010

Aprovado: 11/02/2010

REVISTA BRASILEIRA DE EDUCAÇ̃̃o MÉDICA

$607 \overline{34(4): 607-614 ; 2010}$
'Centro Universitário de Volta Redonda, Volta Redonda, RI, Brasil.

"Fundação Oswaldo Cruz, Rio de Janeiro, RJ, Brasil.

\section{RESUMO}

O conhecimento sobre temas de Genética e Biologia Molecular, nos últimos anos, vem crescendo de maneira exponencial, demandando constante atualização, principalmente se considerarmos que, ao final do período de graduação, muito desse conhecimento está desatualizado. O Quiz de Genética e Biologia Molecular (GBM) foi proposto como nova ferramenta de ensino para complementar a abordagem dessa temática no ensino de ciências da saúde. Elaborado por alunos dos cursos de Medicina e Sistemas de Informação do UniFOA orientados pelos professores, o Quiz foi aplicado e avaliado por 159 alunos do terceiro período de Medicina. Os resultados mostraram excelente aceitação pelos alunos submetidos à ferramenta, apontando principalmente um aumento de interesse nos temas abordados e a possibilidade de reconhecimento das deficiências específicas de subtemas de cada aluno, facilitando correções no processo de aprendizagem. O Quiz surge como um novo instrumento didático que será atualizado e direcionado para as deficiências encontradas pelos alunos e ofertado de maneira presencial ou a distância.

Knowledge of genetics and molecular biology has improved so much in recent years that it requires constant updating, especially considering that a major portion of the knowledge acquired during undergraduate training is outdated by the end of the course. A quiz on genetics and molecular biology was proposed as a new tool to deal with this issue in health sciences teaching. The quiz, developed by students in the courses on medicine and computer studies at UniFOA and oriented by their teachers, was applied and evaluated by 159 third-year medical students. The results showed excellent acceptance by the students, indicating increasing interest in the topics presented and the possibility of identifying each student's specific knowledge needs, thus facilitating feedback into the learning process. The quiz is a new teaching tool that will be updated and focused on the students' knowledge gaps, and will be offered as an e-learning or distance learning system. 


\section{INTRODUÇÃO}

Nos últimos anos, o conhecimento sobre temas de Genética e Biologia Molecular na área de saúde vem crescendo de maneira exponencial, demandando constante atualização, principalmente se considerarmos que, ao final do período de graduação, muito desse conhecimento já está desatualizado. A sala de aula, quando utilizada apenas como local de transmissão de conhecimento, torna-se pequena frente à necessidade de educação continuada.

Conscientes da rapidez com que a informação passada em sala de aula se torna obsoleta, da necessidade de um material pedagógico mais interativo para cultivar o interesse da temática em Genética e Biologia Molecular e da busca de atualização contínua, professores e alunos idealizaram uma nova ferramenta de ensino, partilhando de uma ideia comum: a utilização da informática. Numa sociedade de bases tecnológicas, com mudanças contínuas, em ritmo acelerado, não é possível ignorar as alterações que as tecnologias da informação e da comunicação provocam na forma como as pessoas veem e apreendem o mundo, bem como desprezar o potencial pedagógico que tais tecnologias apresentam quando incorporadas à educação.

O uso do computador na graduação médica ganhou popularidade nas úlltimas duas décadas. Esse tipo de aprendizagem é atraente por diversos motivos, incluindo a eficiência no fornecimento dos conteúdos em diferentes locais, a flexibilidade oferecida ao aluno, a facilidade de revisão do conteúdo e a possibilidade de atualização constante ${ }^{1}$. Devemos, portanto, reconhecer o papel fundamental na utilização de ambientes informatizados no processo de ensino-aprendizagem. Com isso, já consideramos o computador como um instrumento valioso no processo continuado de aprendizagem, e, portanto, cabe à escola utilizá-lo de forma coerente com uma proposta pedagógica atual e consistente.

A história do desenvolvimento do software educacional mostra que os primeiros programas nessa área são versões computadorizadas do que acontece na sala de aula. Porém, à medida que a utilização desse recurso se dissemina, outras modalidades de uso vão se desenvolvendo. Assim, o atual emprego do computador na educação não o caracteriza como "máquina de ensinar", mas como uma ferramenta de complementação, aperfeiçoamento e possível mudança na qualidade de ensino².

A utilização de duas ou mais ferramentas de ensino, combinando métodos diferentes, como a associação entre um software educacional e o modelo clássico e presencial de aprendizado, se insere na definição de blended learning ${ }^{3}$. De acordo com Elliot Masie, pesquisador influente do aprendizado mediado pela informática, blended learning compreende o ofereci- mento de diferentes opções aos alunos, o que lhes proporciona a oportunidade de se adequar ao método que melhor lhes convier ${ }^{4}$.

Segundo Valente (1998), para a implantação do computador na educação são necessários quatro ingredientes básicos: o computador, o aluno, o professor capacitado para usar o computador como meio educacional e o software educativo, tendo todos igual importância ${ }^{2}$. Os softwares educativos vêm sendo criados e apresentados em diversas áreas da Medicina há algum tempo, já existindo no Brasil trabalho semelhante envolvendo a temática em Genética ${ }^{5}$, realizado em 1998 na Universidade Estadual de Campinas.

Com base nos conceitos expostos, idealizou-se um software educacional que estimulasse a autoavaliação e o aprendizado dos alunos em Genética e Biologia Molecular, criando-se, assim, o Quiz de Genética e Biologia Molecular (GBM). Sua utilização propõe facilitar o aprendizado do aluno e tornar o ensino mais dinâmico, podendo até aumentar o interesse pela temática, auxiliando, dessa forma, o processo de ensino-aprendizagem. O dicionário de língua inglesa Oxford ${ }^{6}$ apresenta como resultado de busca da palavra quiz o seguinte significado: entretenimento baseado em perguntas e respostas; que pode ser complementado pelo dicionário Cambridge ${ }^{7}$, que o define como jogo composto por perguntas e respostas que pode ser usado como um teste informal. Com isso, a elaboração de um roteiro de perguntas e respostas ricas em informações cuidadosamente arranjadas, abordado de maneira informal, lúdica e associado aos recursos da informática, um Quiz, foi proposta como uma possível ferramenta pedagógica.

Diante do exposto, o presente trabalho teve por objetivo avaliar a validade da elaboração de um Quiz interativo como nova ferramenta de ensino, no auxílio do processo de aprendizagem dos alunos na disciplina de Genética e Biologia Molecular do UniFOA.

\section{MÉTODOS}

A metodologia utilizada na elaboração do material foi a construção coletiva. Os acadêmicos criaram, a partir da proposta de temas pelos professores, um material com grande oportunidade de aprendizado para os próprios autores, graduandos do curso de Medicina e do curso de Sistema de Informação.

O público-alvo em que foi aplicado o Quiz foram os alunos da Faculdade de Medicina do Centro Universitário de Volta Redonda (UniFOA), que cursavam a disciplina de Genética e Biologia Molecular. O projeto foi aprovado pelo Comitê de Ética em Pesquisa em Seres Humanos do UniFOA.

Ex-alunos da disciplina, orientados pelos professores da mesma, elaboraram um roteiro de estudo baseado em pergun- 
FIGURA 1

Fotos de páginas do Quiz

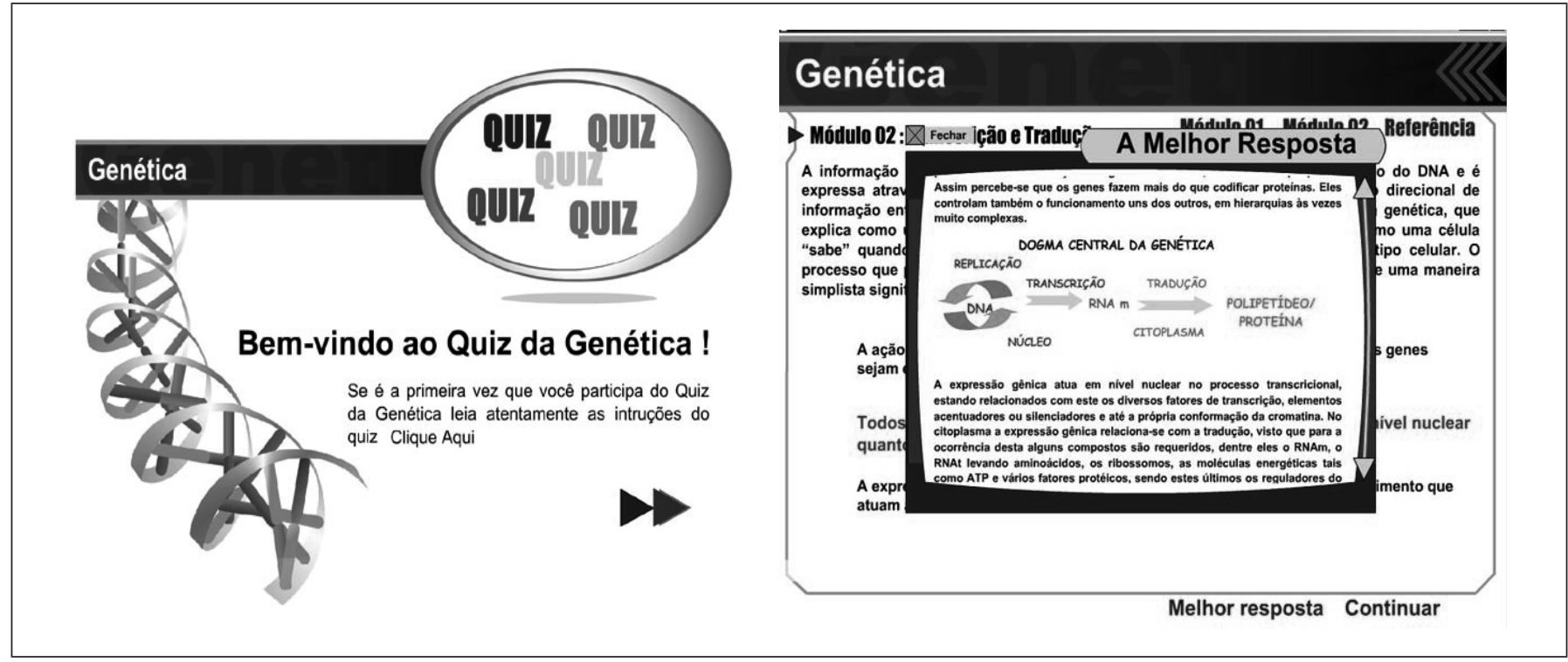

tas e respostas (Quiz) sobre temas específicos. Para a elaboração do Quiz, livros, artigos científicos indexados e publicações eletrônicas de instituições educacionais reconhecidas foram utilizados como referência bibliográfica. Os módulos abordados no Quiz foram aqueles considerados pelos alunos / autores como os mais relevantes, incluindo: Ácidos Nucleicos, Transcrição e Tradução, Divisão Celular, Citogenética, Herança Multifatorial e Herança Mendeliana.

Quanto à metodologia didática, as perguntas foram desenvolvidas segundo um modelo adaptado do Programa de Revisão e Educação Pediátrica ${ }^{8}$ (Pediatric Review and Education Program - American Academy of Pediatrics), com introdução bem estruturada de caráter instrutivo e objetivo, dispondo de três opções, das quais uma com a melhor resposta. Foi elaborado um total de 12 perguntas por tema abordado. Os módulos foram preparados em formato de Quiz, utilizando o programa Macromedia FLASH MX - ferramenta de desenvolvimento/animação WEB para a criação e elaboração de designs, visando agregar valor ao conhecimento dos alunos com boa acessibilidade.

O Quiz foi aplicado no laboratório de informática, sob a supervisão de professores responsáveis pela disciplina e de alunos responsáveis pelo projeto. O Quiz foi aplicado aos alunos que cursavam a disciplina de 2006 a 2007, antecedendo sempre a primeira avaliação semestral. Os alunos que aceita-

Figura 2

Algoritmo da metodologia usada no trabalho. SI: Sistema de Informações

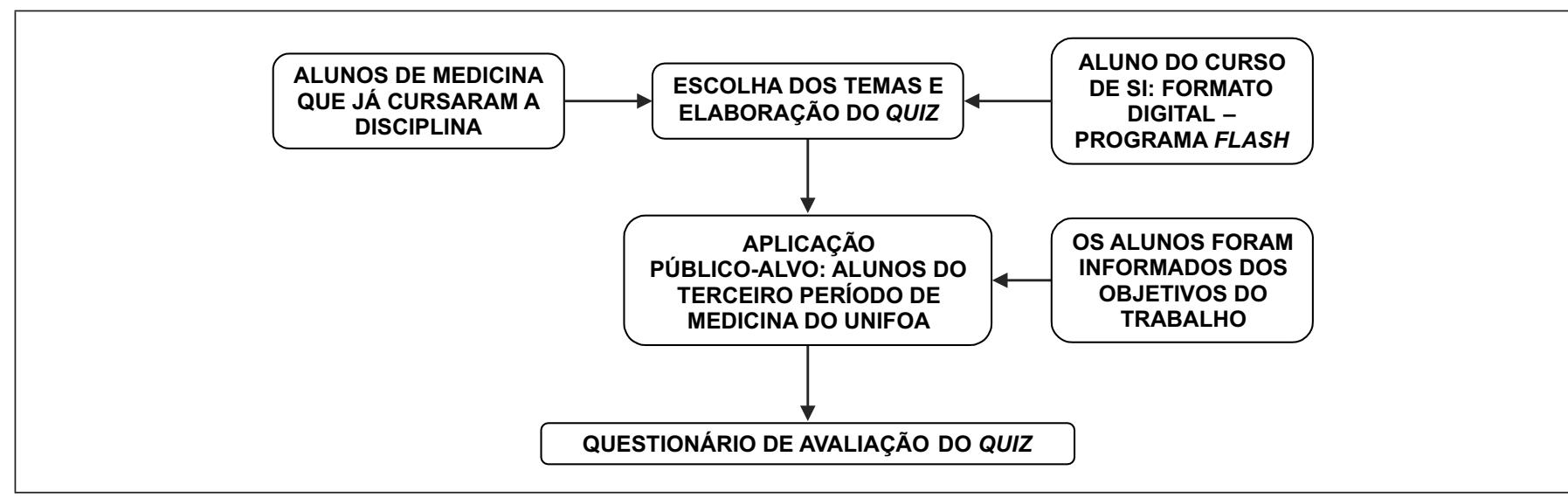

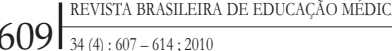


ram participar do Quiz assinaram o Termo de Consentimento Livre e Esclarecido. Foram disponibilizados 90 minutos para a resolução de dois módulos do Quiz: Ácidos Nucleicos e Transcrição e Tradução totalizaram 24 questões, e os alunos tinham uma única chance de responder a cada pergunta. As notas obtidas no Quiz foram armazenadas e posteriormente utilizadas para avaliar o rendimento dos alunos. Após a resolução do Quiz, os alunos tiveram acesso às respostas, embasadas nas referências bibliográficas, com comentários mais extensos e detalhados sobre as questões, contendo exemplos clínicos, correlações com outras disciplinas, curiosidades sobre o tema, animações e ilustrações.

Um questionário de autoavaliação foi entregue aos alunos participantes após a primeira avaliação semestral, posterior, portanto, à realização da atividade com perguntas referentes ao Quiz. O questionário era composto por 18 questões fechadas, além de um espaço reservado a críticas e sugestões dos alunos. Algumas questões pediam ao aluno para atribuir uma pontuação entre 0 e 10 à variável estudada, sendo denominado grau de importância. Ficaram responsáveis pela aplicação do questionário os professores da disciplina e os alunos responsáveis pelo projeto.

Um banco de dados foi criado no programa Microsoft Excel, e a análise de dados foi realizada através de apresentação da frequência absoluta e da frequência percentual.

\section{RESULTADOS}

Após a realização do Quiz, os autores tiveram acesso aos resultados individuais e puderam, a partir daí, observar os percentuais de erro e acerto de cada módulo. Nessa análise, observou-se que os temas com maiores percentuais de erro se referiam a DNA viral, replicação, estrutura química do nucleotídeo e questões a respeito da transcrição e tradução, como: dogma central da genética, Cap 5', cauda Poli A e elemento promotor.

Foram respondidos 159 questionários de autoavaliação. Constatou-se que $100 \%$ ( $n=159)$ dos alunos relacionaram os conteúdos abordados no Quiz com os assuntos discutidos em aula. Todos os alunos $(n=159)$ afirmaram também que as questões do Quiz aumentaram de alguma forma o conhecimento sobre os temas abordados, tendo sido atribuído para tal um grau de importância de 7,41 pontos, num total de 10 .

O grau de importância conferido ao conhecimento e domínio do conteúdo da disciplina antes da realização do Quiz foi de 5,97 pontos, valendo dizer que apenas $22,64 \%(n=36)$ dos alunos afirmaram ter estudado antes da realização do Quiz. Um total de 98,74\% ( $\mathrm{n}=157)$ dos alunos afirmaram que as perguntas, da maneira como foram elaboradas, serviram como fonte de informação, atribuindo um grau de importância de 7,67 pontos.

Quando questionados sobre o nível de dificuldade das questões, os alunos atribuíram um grau de importância de 6,05 pontos. Todavia, $73,58 \%(n=117)$ dos alunos afirmaram ter apresentado maior dificuldade em algum tema especial. Os temas mais citados foram, no geral, relativos à transcrição e tradução, existindo queixas também quanto às questões que envolviam bases nitrogenadas, estrutura química do nucleotídeo e direcionamento das fitas dos ácidos nucleicos na replicação.

Apenas $57,23 \%(n=91)$ dos alunos notaram a presença de conteúdos interdisciplinares, tendo sido citadas principalmente as disciplinas de Bioquímica, Histologia e Embriologia.

A respeito da formatação eletrônica do Quiz, 99,3\% ( $\mathrm{n}=$ 158) dos alunos afirmaram considerá-la de fácil compreensão. Os mesmos 99,3\% afirmaram que a forma como foram apresentados os módulos e questões também foi de fácil compreensão.

TABELA 1

Distribuição dos alunos em faixas de pontuação do grau de importância atribuído a cada questionamento. Volta Redonda, 2007

\begin{tabular}{|c|c|c|c|}
\hline \multirow{2}{*}{ Questões } & \multicolumn{3}{|c|}{ Faixas de pontuação } \\
\hline & $0-4$ & $5-7$ & $8-10$ \\
\hline Aumento do conhecimento sobre os temas abordados & $6,92 \%(11)$ & $40,88 \%(65)$ & $52,20 \%(83)$ \\
\hline Perguntas servindo como fonte de informação & $5,10 \%(8)$ & $36,94 \%(58)$ & $57,96 \%(91)$ \\
\hline Conhecimento e domínio do conteúdo antes da realização do Quiz de GBM & $13,84 \%(22)$ & $70,44 \%(112)$ & $15,72 \%(25)$ \\
\hline Nível de dificuldade das questões & $16,35 \%(26)$ & $64,15 \%(102)$ & $19,50 \%(31)$ \\
\hline Valor da metodologia como forma de ensino a distância & $0,91 \%(1)$ & $18,18 \%(20)$ & $80,91 \%(89)$ \\
\hline Relevância do Quiz de GBM para o rendimento acadêmico & $6,29 \%(10)$ & $48,43 \%(77)$ & $45,28 \%(72)$ \\
\hline Relevância dos temas abordados para a vida profissional & $5,66 \%(9)$ & $49,69 \%(79)$ & $44,65 \%(71)$ \\
\hline Atendimento das expectativas em relação ao Quiz de GBM & $3,14 \%(5)$ & $35,85 \%(57)$ & $61,01 \%(97)$ \\
\hline
\end{tabular}


Quando questionados sobre a manutenção do Quiz no programa de aula, 99,3\% dos alunos concordaram com essa medida. Além disso, foi atribuído um grau de importância de 8,26 pontos ao valor dessa metodologia como forma de apoio à disciplina de maneira não presencial.

Os alunos atribuíram à relevância do Quiz para o rendimento acadêmico um grau de importância de 7,04 pontos. Da mesma forma, atribuíram um grau de importância de 7,19 pontos à relevância dos temas abordados para a vida profissional.

A extensão do Quiz a outros capítulos da disciplina de Genética de Biologia Molecular foi aprovada por 98,74\% ( $\mathrm{n}=157)$ dos alunos. De forma semelhante, a extensão da metodologia do Quiz a outras disciplinas também foi aprovada por 99,3\% dos alunos.

No final do questionário, 85,53\% $(n=136)$ dos alunos consideraram que houve aumento do interesse pela disciplina após a realização do Quiz. Além disso, os alunos atribuíram um grau de importância de 7,94 pontos quando questionados se as expectativas em relação ao Quiz haviam sido atendidas.

No espaço reservado às críticas e sugestões, alguns alunos expressaram sua opinião. Grande parte enfatizou a vontade de extensão do Quiz a outras disciplinas, tendo sido comentada também a forma de aprendizado mais lúdica, interativa e alternativa.

Parte dos alunos informou ter identificado sua dificuldade em algum tema específico com ajuda do Quiz.

\section{DISCUSSÃO}

Os alunos que se autoavaliaram conseguiram identificar as maiores dificuldades em assuntos específicos, sendo os temas abordados nas questões com maiores percentuais de erro os mesmos citados pelos alunos quando questionados a respeito do nível de dificuldade das questões. Portanto, as dificuldades foram identificadas tanto pelos autores quanto pelos próprios alunos, havendo uma concordância das observações. Esse fato realça a possibilidade de os alunos, quando testados, mesmo informalmente, constatarem suas deficiências, identificando de forma correta pontos a serem trabalhados e melhorados.

Quanto ao benefício didático das atividades complementares, Ernst e Colthorpe ${ }^{9}$, da Universidade de Queensland, na Austrália, propõem que essas atividades - porque expõem com maior ênfase determinados itens - podem ter seus benefícios extrapolados a graus ainda maiores quando tratamos de alunos menos preparados, que na leitura didática tradicional apresentam dificuldades para identificar os tópicos mais relevantes do conteúdo abordado.

Virvou et al. ${ }^{10}$, da Universidade de Piraeus, na Grécia, mostraram o impacto desse modelo de ensino no aprendiza- do, em artigo original que avaliava a aplicabilidade de um software educativo usado de forma complementar ao ensino tradicional. A primeira conclusão dos autores, após análise objetiva do desempenho acadêmico dos alunos antes e depois do uso do software educacional, está de acordo com a ideia de Ernst \& Colthorpe ${ }^{9}$. Os dois estudos consideraram o material didático complementar uma ferramenta que exerce maior impacto sobre o aprendizado nos alunos com pior rendimento acadêmico. Além disso, Virvou et al. ${ }^{10}$ não encontraram diferenças significativas na melhoria do aprendizado dos alunos que já tinham bom desempenho, mas também enfatizaram que o software não os prejudicou. Os mesmos autores sustentaram a opinião de que bons alunos terão bons desempenhos em qualquer circunstância, enquanto aqueles com piores rendimentos serão beneficiados por instrumentos que propiciem ambientes de motivação extra, como um software educativo interativo.

Sancho et al. ${ }^{11}$ e Lewin el al. ${ }^{1}$ realizaram trabalhos utilizando o modelo de blended learning para otimizar o aprendizado de graduandos de cursos de saúde, principalmente em disciplinas do ciclo básico. Em ambos os trabalhos, os achados em relação à combinação de metodologias de ensino foram positivos. Sancho et al. ${ }^{11}$ enfatizaram que o blended learning, além de beneficiar o aprendizado, atrai a atenção e o interesse do aluno ao considerar a utilização de diversos cenários. Lewin et al. ${ }^{1}$ atribuíram o sucesso de seu trabalho ao uso criativo da informática e à natureza prática do material por eles construído, além de proporem a ampliação desse formato de ensino às disciplinas do ciclo clínico.

A respeito da forma como as questões foram elaboradas, com introdução de caráter instrutivo e objetivo, cerca de $98 \%$ dos alunos avaliaram que a mesma serviu como fonte de informação, atribuindo um grau de importância de 7,67 pontos, com $57 \%$ dos alunos na faixa de 8 a 10 pontos. Esse achado explora a similaridade entre o Quiz de GBM e o Programa de Revisão e Educação Pediátrica (PREP) ${ }^{8}$, que serviu de modelo metodológico para a elaboração do conteúdo. Na exposição da forma de ensino proposta, o PREP apresenta em seus cadernos de exercícios, como função do conjunto "pergunta - melhor resposta", a leitura do questionamento e posteriormente do comentário. Aqui, não se discute somente a lógica por trás da melhor resposta, mas também o motivo pelo qual as demais opções estão erradas, considerando-se este o ponto principal para o estímulo da autoavaliação. O PREP, que completou 30 anos em 2009, é apontado pela Academia Americana de Pediatria como o padrão ouro para o preparo dos médicos pediatras americanos e para sua educação continuada. Mary Ellen Ri$\mathrm{msza}^{12}$, editora do PREP, acredita que a revisão e a autoavalia- 
ção oferecem aos pediatras a oportunidade de identificarem suas fraquezas e de escolherem, a partir daí, a melhor forma de ampliarem seus conhecimentos.

O blended learning preconiza a combinação de métodos de ensino de forma que o aluno tire o melhor proveito da estratégia ao "ler, refletir e responder" às questões propostas ${ }^{3}$. Mas, para alcançar seus objetivos, o blended learning deve ser composto por boas combinações. Isto significa que não basta apenas escolher uma série de informações agrupadas e oferecê-las aos alunos. Segundo Assmann ${ }^{13}$, a geração de dados não estruturados não conduz automaticamente à criação de informação, e nem toda informação pode ser equiparada a conhecimento. Toda informação pode ser classificada, analisada, refletida e processada de várias maneiras para, então, gerar conhecimento. Sob essa ótica, podemos ponderar que um roteiro esquematizado de perguntas e respostas, quando elaborado de forma cuidadosa e utilizado como ferramenta complementar, só vem auxiliar os alunos no processo de ensino-aprendizagem e na construção de conhecimento.

Outro ponto a destacar é a metodologia do Quiz como forma de ensino não presencial, complementando as atividades acadêmicas de rotina, que recebeu um grau de importância de 8,26 pontos, com $71 \%$ dos alunos situados na faixa de pontuação entre 8 e 10 pontos. A educação a distância é caracterizada como o processo de ensino-aprendizagem, mediado por tecnologias, na qual professores e alunos estão separados espacial e/ou temporalmente ${ }^{14}$. Mesmo não estando juntos de maneira presencial, podem estar conectados por tecnologias como a internet, o correio, o rádio, a televisão, o vídeo, o CD-ROM e tecnologias semelhantes. Sob esse prisma, propõe-se a utilização do Quiz como uma ferramenta de complementação e aperfeiçoamento do ensino, seja ele presencial ou a distância.

A formatação eletrônica do Quiz e a maneira como foram expostos os módulos e as questões foram avaliadas por $99 \%$ dos alunos como de fácil compreensão. Provavelmente, a forma de apresentação do Quiz serve como um diferencial desse tipo de ferramenta de ensino. Lih-Wei Lei et al. ${ }^{15}$ consideram o aprendizado visual obrigatório em diversas etapas da educação médica, como acontece na anatomia, histologia, radiologia, urianálise e hematologia. Por que não considerarmos disciplinas de cunho molecular, como genética, bioquímica e biologia molecular, participantes desse grupo? A compreensão espacial do processo descrito pode se tornar mais fácil com a presença de animações e ilustrações, principalmente quando estas são montadas por softwares específicos e disponibilizadas em formatações eletrônicas bem organizadas.
Ainda quanto ao formato eletrônico de apresentação do Quiz, alguns alunos sugeriram a possibilidade de retorno à questão anterior durante a resolução do mesmo. Contudo, a formatação com essa sequência contínua de perguntas foi disponibilizada apenas durante a fase de avaliação do Quiz, já tendo sido realizadas mudanças que possibilitam retornar à questão anterior em possíveis utilizações futuras.

A atribuição de um grau de importância de 7,04 pontos para a relevância do Quiz de GBM no rendimento acadêmico e de 7,19 pontos para a relevância dos temas abordados para a vida profissional demonstra a consciência dos alunos quanto à importância da genética no futuro das ciências médicas. Essa opinião dos alunos avaliados condiz com o pensamento de Beckhauser et al. ${ }^{16}$, que mostram as disciplinas do ciclo básico, de cunho científico e estrutural, como o alicerce para a composição do entendimento do ser humano como um conjunto composto por um sistema biológico e uma estrutura psicológica e social. Além disso, o aumento de interesse pela disciplina atestado pelos alunos vai ao encontro da ideia de Wannmacher ${ }^{17}$, na qual os professores das disciplinas básicas se empenham em adequar uma visão integrada de todas as disciplinas e em convencer os alunos de que os conteúdos de suas disciplinas terão certamente uma aplicação prática em algum momento da carreira acadêmica e profissional.

Entre os objetivos do Quiz também se encaixa a tentativa de formação de um material mais interativo, no qual exista a possibilidade da comunicação de dupla via, da "teoria dialógica" de Paulo Freire ${ }^{18}$, pois somente através do diálogo o processo de educação se consolida, sendo indispensável a interação professor-aluno. O Quiz experimenta esse conceito justamente na colocação de ex-alunos como autores, posição em que dispunham de total liberdade para argumentar e dialogar com seus professores.

O material produzido até o momento será publicado pela Editora FOA no formato de um software educacional em CD-ROM. Atuais monitores de diversas disciplinas manifestaram o desejo de criar e ampliar os conteúdos desse projeto, abordando novos temas e ampliando a interdisciplinaridade. Percebemos que existe uma premente necessidade de integrar conhecimentos na área médica, tanto nas disciplinas básicas quanto nas clínicas, e assim ultrapassarmos o modelo de ciclos para um modelo mais integrado.

Apesar de ainda não ter sido feita uma avaliação concreta e substanciada da representação e do impacto do Quiz sobre o desempenho dos alunos até o momento da publicação deste artigo, os alunos que cursam a disciplina vêm usando continuamente o material produzido, como fonte de estudo e aprendizado, principalmente em apoio às atividades de monitoria 
da disciplina de Genética e Biologia Molecular no UniFOA. O objetivo principal do projeto foi o incentivo à leitura e ao estudo de temas relacionados de maneira desafiadora e lúdica. A publicação do material proporcionará aos autores uma avaliação mais longitudinal do processo, com melhor avaliação de sua contribuição no ensino-aprendizagem.

\section{CONCLUSÃO}

Na avaliação da validade do Quiz, 99\% dos alunos se manifestaram a favor da manutenção desse instrumento no plano de aula, assim como de sua extensão a demais capítulos da genética e biologia molecular e até a outras disciplinas. Atribuímos o sucesso do Quiz ao uso criativo da tecnologia informática e à dinâmica implícita na atividade. Dessa maneira, concluímos que o Quiz surge como um novo instrumento didático complementar, que pode ser constantemente atualizado e direcionado para as dificuldades encontradas, uma vez que o projeto pode ser continuado pelos ex-alunos da disciplina, reforçando a ideia de que educadores devem considerar a combinação de outras estratégias de ensino para a construção do conhecimento.

\section{REFERÊNCIAS}

1. Lewin LO, Singh M, Bateman BL, Glover PB. Open Access Improving education in primary care: development of an online curriculum using the blended learning model. BMC Med Educ [periódico na internet]. 2009 [acesso em out. 2009];9:33. Disponível em: http://www.biomedcentral. com/content/pdf/1472-6920-9-33.pfd

2. Valente JA. Diferentes usos do Computador na Educação. 2ª ed. Campinas: Unicamp; 1998.

3. Kieran Walsh. Quality improvement report. BMJ. 2005;330:829.

4. 4. Epic White Papers. Blended learning and learning desing. Blended learning [on line]. Epic; 52. [acesso em out. 2009]. Disponível em: http://www.epic.co.uk/assets/files/wp_blended_learning.pdf.

5. Volpe RM, Aquino MTB, Norato DY. Muitimedia system based don programmed instruction in medical genetics: construction and evaluation. Int J Med Inform. 1998;50(13):257-9.

6. Oxford Dictionary [homepage]. AskOxford.com. Quiz. [on line]. [acesso em nov.2009] Disponível em: http://www. askoxford.com/asktheexperts/faq/aboutwordorigins / quiz?view=uk.

7. Cambridge. Cambridge Dictionaries Online [homepage]. Quiz. [on line]. [acesso em nov. 2009]. Disponível em: http://dictionary.cambridge.org/define. asp?key=64986\&dict=CALD.
8. American Academy of Pediatrics. Pediatrics Review and Education Program (PREP) 2009 [online]. [acesso em out. 2009]. Disponível em: http://www.aap.org/profed/prep. htm.

9. Ernst $\mathrm{H}$, Colthorpe K. The efficacy of interactive lecturing for students with diverse science. Backgrounds. Adv Physiol Educ. 2007;31(1):41-4.

10. Virvou M, Katsionis G, Manos K. Combining Software Games with Education: Evaluation of its Educational Effectiveness. Educational Technology \& Society. 2005;8(2):54-65.

11. Sancho P, Corral R, Rivas T, González MJ, Chordi A, Tejedor C. Instructional Design and Assessment: A Blended Learning Experience for Teaching Microbiology. Am J Pharm Educ. 2006; 70(5):Article 120. [cerca de 9 páginas].

12. Kennedy K. Gold standard for PREParation: Pediatrics Review and Education Program, PIR mark 30 years of keeping pediatricians actively learning. AAP News. 2009;30(2):13.

13. Assmann EH. Reencantar a Educação: rumo à sociedade aprendente. Petrópolis: Vozes; 1999.

14. Cassol MP. O Intercâmbio do Saber: Um estudo de caso sobre a tutoria da Universidade do Vale do Itajaí - UNIVALI. Florianópolis, 2002. Mestrado [dissertação] — Universidade Federal de Santa Catarina.

15. Lei WL, Winn W, Scott C, Farr A. Evaluation of Computer-Assisted Instruction in Histology: Effect of Interaction on Learning Outcome. Anat Rec B New Anat. 2005;284(1): 8-34.

16. Beckhauser PF, Almeida EM, Zeni ALB. A Bioquímica como disciplina Básica em Medicina: Esquemas e Soluções de Problemas. Rev Bras Educ Méd. 2005;29(3):161-6.

17. Wannmacher CMD. Ensinando Bioquímica Para Futuros Médicos. Revista Brasileira de Ensino em Bioquímica e Biologia Molecular. 2001;1:12.

18. Gadotti M. Convite à Leitura de Paulo Freire. São Paulo: Scipione; 1991.

\section{CONTRIBUIÇÃO DOS AUTORES}

João Miguel de Almeida Silva e Rafael V. Canedo, responsáveis pela elaboração do conteúdo teórico das questões e das melhores respostas, pela execução do projeto e pela análise estatística. Thomas Alves de Souza Abrantes responsável pela formatação eletrônica do Quiz e pela elaboração da arte gráfica das animações e gravuras. Rafael Teixeira dos Santos responsável pela orientação e supervisão do aluno. Renata Almeida Souza, responsável pela revisão técnica do conteúdo elaborado pelos alunos João Miguel de Almeida Silva e Rafael Vieira Canedo e Claudia Yanada Utagawa, responsável pela revisão de todo material do Quiz e pela orientação dos alunos. 


\section{CONFLITO DE INTERESSES}

Declarou não haver.

\section{ENDEREÇO PARA CORRESPONDÊNCIA}

João Miguel de Almeida Silva

Centro Universitário de Volta Redonda.

Av. Paulo Erlei Alves Abrantes, 1325

Três Poços - Volta Redonda

CEP. 27240-000 RJ

E-mail: joaomiguel87@yahoo.com.br 